\title{
Project-based Learning Approach to Marketing Competencies Development
}

\author{
Radim Dušek ${ }^{1, *}$ \\ ${ }^{1}$ VŠTE, Faculty of Corporate Strategy, Department of Tourism and Marketing, České Budějovice, \\ Czech Republic
}

\begin{abstract}
Due to the requirements for matching the needs of employers with the job applicants' skills, companies increasingly tend to use a key competency-based approach to select new marketers. The aim of this paper is to determine if the project-based learning method has helped developing economic university students' key competencies that are essential in the marketing related jobs. For testing and developing such key competencies, the method of project-based learning have been implemented into the Marketing communication course at the Faculty of Economics, University of South Bohemia in Czech Republic. Results show that innovated course had a positive effect especially on the development of abilities to work effectively in team, assessing and analysing information or work independently.
\end{abstract}

Keywords: project-based learning; marketing competencies; key competencies; development; pedagogy

\section{Introduction and Literature Review}

Marketing is everything, but it can be interpreted by various authors or experts with hundreds of different definitions. Concurrently this concept can be understood by entrepreneurs differently and inconsistently. For a small business, it is usually a paid advertisement on social networks or a new catalogue [1]. In the case of global corporations, this is already an almost scientific approach to how to tie the customer to their products, and marketing costs are among the highest.

With the growing importance of marketing, the demand of enterprises for more or less experienced employees who will prepare and implement their marketing strategies is also increasing, as well as the rising number of job applicants. Due to the requirements for matching the needs of employers with the individual job applicant's skills, HR managers increasingly tend to use a key competency-based approach to select the best candidates $[2,3]$.

Competencies can be defined as a generic complex of knowledge, values and attitudes, but primarily life skills such as problem solving, communication, collecting and analysing information, ability to work independently, leadership, creativity, ability to cooperate effectively and lifelong learning [4,5]. These competencies allow individuals to act

\footnotetext{
*Corresponding author: dusek@mail.vstecb.cz
} 
adequately and efficiently within the various professional and personal life situations. They represent and incorporate a wide range of long term qualifications and requirements for a flexible response to the changing labour market demands and they also ensure maximum performance in the defined tasks [6].

In the developed countries, efforts have been put by universities for business or economic degree to prepare graduates who want to be marketers to meet actual labour market requirements. These requirements are no longer based only on theoretical knowledge, but especially on higher level of abilities which provides a framework to the behaviour and skills that are expected of competent marketers in various types of marketing specializations $[7,8]$. Such competency-based approach consists of the desired framework of the individuals' key competencies for specific positions by means of a competency model as a basis for the selection of suitable applicants for a given position within an organization, for example in marketing department [9-11].

To be competent and capable in the marketing related jobs, authors refer mainly to this set of key marketing competencies [12-16]:

a) Creative thinking;

b) Communication;

c) Working independently;

d) Effective team collaboration;

e) Leadership;

f) Negotiation;

g) Assessing and analysing information;

h) Ability to manage a budget;

i) Public speaking;

j) Ability to work under pressure.

Most of these competencies are behavioural, so if students have certain basic individual capabilities, their competencies can be developed throughout higher education [17], so obvious next step in the competencies development is to find and implement suitable pedagogy methods enabling students to develop mentioned competencies. There are plenty of methods that have been proven to help in that, for example case studies [18], projectbased learning methods [19, 20], experimental and problem-based learning [21] or business simulation games [22].

Project-based learning method is often considered as the one of the most suitable pedagogy for students' key competencies development. This approach can be characterized by creating the students' research teams to work on long-term projects (usually one or two semesters), which are connected to real world business practice and designed to solve the actual business tasks and problems [23, 24]. Advantages of the project-based learning method can be described as follows [25]:

1. Integrating wide range of skills and knowledge.

2. Connecting the students' skills and knowledge with the experience that will help to increase effectiveness of the learning process.

3. Activating students for lifelong learning.

4. Developing students' ability to communicate and cooperate in a team.

5. Developing students' organizational and time management skills.

\section{Methodology}

The aim of this paper is to determine if the project-based learning method has helped developing economic university students' key competencies that are essential in the marketing related jobs. For testing and developing chosen key marketing competencies, 
the method of project-based learning have been implemented into the Marketing communication course at the Faculty of Economics, University of South Bohemia in Czech Republic. As this course is in the final year of the study, it effectively serves to synthesing knowledge and skills from various marketing related courses from the five-year study in the field of trade and marketing. In lectures throughout the semester, students at first obtained enough relevant and actual theoretical background about marketing communication mix with examples of new trends effectively used by marketing experts. Then, on the first course seminar the teams (2-3 students per team) were created and each team had to choose one specific project. The concrete projects were specified by the global company that runs automotive factory in South Bohemia and its marketing managers were interested to cooperate with the faculty on this new project. At the remaining seminars, each team had to work on the project independently (but under the supervision of the course teacher author of this paper), create a final report with the relevant recommendations and then introduce the project results to the company managers at the end of the semester.

The topics specified by the company were focused on:

a) marketing communication mix for new products,

b) HR marketing communication,

c) marketing communication strategy for company's events.

To find out effects of the project-based learning method on Marketing communication course's students, the research is aimed at determining whether and how this experience influenced the specific competencies development. So the following research question was determined:

Which marketing competencies, that are often required by marketing related jobs, have been developed in students by the project-based learning method experience?

Based on the course structure and project topics, these six marketing competencies were chosen and analysed based on the participants' self-evaluation data:

1. Assessing and analysing information

2. Communication

3. Creative thinking

4. Effective team collaboration

5. Leadership

6. Working independently

Data from all participants (76 students/28 teams) of Marketing communication course have been collected during both summer semesters 2018 and 2019 with the questionnaire survey right after they finished the course (quantitative, 25 questions, mainly five-point Likert scale, 76 responses).

Excel and R software have been used for the data analysis, namely nonparametric single sample Wilcoxon one-sided test for testing the hypotheses. 


\section{Results}

The assumption was that the project-based learning method experience improved six marketing competencies mentioned above. After finishing the course, students selfevaluated the Marketing communication course's contribution on developing their competency framework on the five-point Likert scale (where 5 = strongly agree; 4 = agree; 3 = undecided; 2 = disagree; 1 = strongly disagree).

Means are shown in Fig. 1. If mean is greater than 3, the course has helped to develop the particular competency. Based on the the students' self-evaluation, it can be argued that the Marketing communication course had a positive effect especially on the development of abilities to work effectively in team and assessing and analysing information. These results correspond to the project tasks and necessary activities, because at first students had to often communicate and meet company managers to obtain enough relevant and comprehensive information about the given problem, analyse it and then start to work on concrete creative solutions or ideas.

To a lesser extent, it helped to develop participants' creative thinking and communication skills. The suggestions and solutions of some teams were very creative, however, these interesting initial ideas were mostly suggested by few more creative participants, and then further developed by other team members. It was clear that in the case of some students, it was not possible to develop their creativity too much with this method, because they are just less competent in this area.

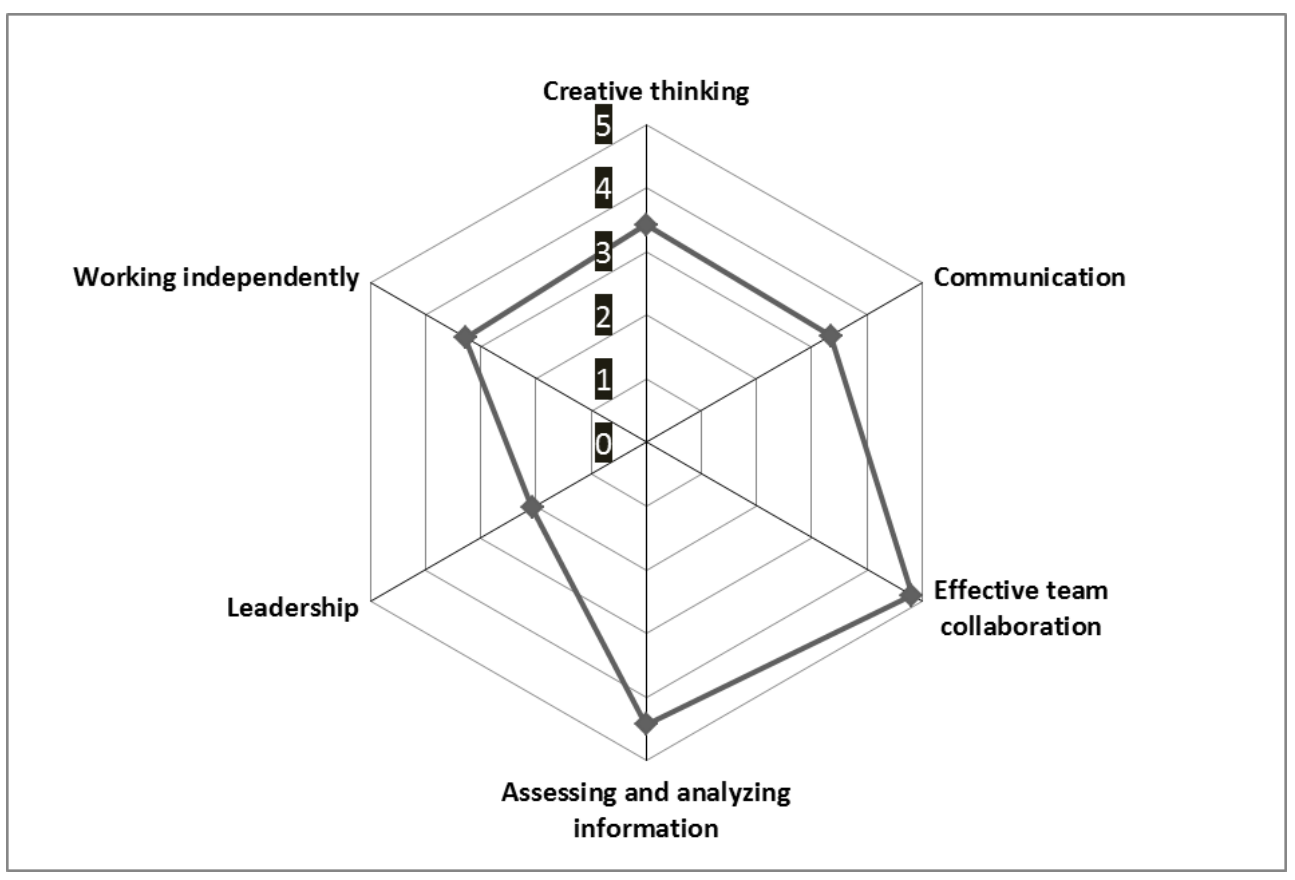

Fig. 1. Level of competencies' development (means, $n=76$ )

Source: Own processing. 
Nonparametric single sample one-sided Wilcoxon test was used to test null hypotheses for all 6 analysed competencies as shown in Tab. 1.

$H_{0}$ : Specific competency mean including $95 \%$ confidence interval is statistically significantly greater than 3 .

$H_{A}$ : non $H_{0}$

Table 1. Results of Wilcoxon test and accepted hypotheses at the $95 \%$ confidence level

\begin{tabular}{|l|l|c|}
\hline Marketing competencies & $\mathbf{p}$-value & Accepted hypothesis \\
\hline assessing and analysing information & $1.753^{-07}$ & $\mathbf{H}_{\mathbf{0}}$ \\
\hline communication & 0.0002 & $\mathbf{H}_{\mathbf{0}}$ \\
\hline creative thinking & 0.0004 & $\mathbf{H}_{\mathbf{0}}$ \\
\hline effective team collaboration & $6.329^{-06}$ & $\mathbf{H}_{\mathbf{0}}$ \\
\hline leadership & 0.419 & $\mathrm{H}_{\mathrm{A}}$ \\
\hline working independently & 0.1736 & $\mathrm{H}_{\mathrm{A}}$ \\
\hline
\end{tabular}

Source: Own processing.

At the $95 \%$ confidence level, the null hypothesis was accepted for these 4 of analysed 6 competencies: assessing and analysing information; communication; creative thinking; effective team collaboration. Mentioned competencies' means including 95\% confidence interval are statistically significantly greater than 3 , so it can be concluded that projectbased learning method experience, according to students' self-evaluation, developed at least four marketing competencies in a certain way.

After only two semesters of Marketing communication course with the use of this alternative pedagogy, obtained findings are important in terms of the possible updating traditional approach to the education process and apply project-based learning methods into the other marketing courses such as marketing research, public relations or strategic marketing. These courses can be actualized to contribute more in terms of developing particular competencies that are demanded by labor market. At the same time, working on real, practical and actual projects helps to develop participants' ability to apply their theoretical background from other completed courses, for example trade, management or economy.

\section{Conclusion}

The aim of this paper is to determine if the project-based learning method has helped developing economic university students' key competencies that are essential in the marketing related jobs. For testing and developing chosen key marketing competencies, the method of project-based learning have been implemented into the Marketing communication course at the Faculty of Economics, University of South Bohemia.

To answer the research question, data from 76 participants of the course during 2018 and 2019 have been collected with the survey after they finished the course. Based on the course structure and project topics, six marketing competencies were chosen and analysed based on the participants' self-evaluation data - assessing and analysing information; communication; creative thinking; effective team collaboration; leadership; working independently.

Results show that innovated course had a positive effect especially on the development of abilities to work effectively in team and assessing and analysing information. These findings are important from the view of the possible updating traditional approach to the education process and apply project-based learning methods into the other marketing 
courses such as marketing research, public relations or strategic marketing. These courses can be actualized to contribute more in terms of developing particular key competencies demanded by the actual labour market situation.

\section{References}

1. P. Pillai, Everything is Marketing and Marketing is Everything. The Marketing Review (2012)

2. D. Liebenow, S. Uedelhoven, M. Stricker, J. Nachwei, Quality in Competency Management: An Explorative Study to Develop a Benchmark for Competency Modeling and Competency Models. Zeitschrift für Arbeits und Organisationspsychologie, 64, 2, 120-148 (2020)

3. M. R. Weber, J. Lee, A. Crawford, A suggested best practices for enhancing performance of soft skills with entry-level hospitality managers. Anatolia-international journal of tourism and hospitality research, 31, 1, 76-87 (2019)

4. M. Armstrong, Armstong's Handbook of Human Resource Management Practice. Philadelphia: Kogan Page (2011)

5. A. Wiek, L. Withycombe, C. L. Redman, Key competencies in sustainability: a reference framework for academic program development. Sustainability Science, 6, 2, 203-218 (2011)

6. T. Weiss, S. Kolberg, Coaching Competencies and Corporate Leadership. Florida: CRC Press (2003)

7. V. Vojtko, R. Dušek, Filling the gap between theory and practice by business simulation games. Conference Proceedings of the 20th Annual International Conference Enterprise and Competitive Environment, March 9-10, 2017, Mendel University in Brno, 908-918 (2017)

8. M. Hay, Business schools: a new sense of purpose. Journal of Management Development, 27, 4, 371-378 (2008)

9. D. D. Dubois, W. J. Rothwell, Competency-Based Human Resource Management. California: Davies-Black Publishing (2004)

10. C. J. Gonsalvez, F. L Calvert, Competency-based Models of Supervision: Principles and Applications, Promises and Challenges. Australian Psychologist. 49, 4, 200-208 (2014)

11. M. A. Campion, A. A. Fink, et al, Doing competencies well: best practices in competency modeling. Personnel Psychology. 64, 1, 225-262 (2011)

12. J. Hadrich, New Key Competencies for Authorities, Companies and their Managers Part 2: Obstacles and Success Factors of modern Leadership. Deutsche LebensmittelRundschau, 116, 5, 186-196 (2020)

13. J. M. Loveland, S. A. Thompson, J. W. Lounsbury, D. Dantas, Is diffusion of marketing competence necessary for a market orientation? A comparative investigation of marketing managers and their defining traits. Marketing Intelligence \& Planning, 33, 3, 469-484 (2015)

14. DQ. Xin, X. Zhao, The Construction of College Students Self-marketing Competency Model. Recent advance in statistics application and related areas, vols I and II Proceedings from the 2nd Conference of the International Institute of Applied Statistics Studies, Qingdao, China (2009)

15. M. Rieckmann, Future-oriented higher education: Which key competencies should be fostered through university teaching and learning? Futures, 44, 2, 127-135 (2012)

16. S. Nwankwo, A. Gbadamos. Entrepreneurship Marketing: Principles and Practice of SME Marketing. Oxon: Rouletge (2020) 
17. M. Hay, Business schools: a new sense of purpose. Journal of Management Development, 27, 4, 371-378 (2008)

18. E. Anderson, B. Schiano, Teaching with cases: a practical guide. Harvard Business School Publ, Boston, Mass (2014)

19. W.N. Bender, Project-based learning: differentiating instruction for the 21st centrury. Thousand Oaks: Corwin (2012)

20. R. Maltese, Project Based Learning: 25 Projects for 21st Century Learning. Indianapolis: Dog Ear Publishing (2012)

21. S.R. Tiwari, L. Nafees, O. Krishnan, Simulation as a pedagogical tool: Measurement of impact on perceived effective learning. The International Journal of Management Education. 12, 3, 260-270 (2014)

22. M. Pratt, S. Hahn, Effects of Simulation on Student Satisfaction With a Capstone Course. Journal of Hospitality \& Tourism Education, 27, 1, 39-46 (2015)

23. M. Almulla, The Effectiveness of the Project-Based Learning (PBL) Approach as a Way to Engage Students in Learning. Sage Open, 10, 3 (2020)

24. J. Atkinson, Developing teams through project-based learning. Hampshire: Gower Publishing (2001)

25. R. Dušek, Developing Student's Key Competencies through Cooperation with Enterprises. SHS Web of Conferences - Eurasia: Sustainable Development, Security, Cooperation. 71 (2019) 